\title{
Research on Network Education Method based on the Big Data
}

\author{
M.W. Tang, S.K. Zeng, J.R. Hu \\ School of Mathematics and Computer Science Technology \\ Xihua University \\ Chengdu 610039, China
}

\author{
J. $\mathrm{Hu}$ \\ School of Information Science and Technology \\ Southwest Jiaotong University \\ Chengdu 610031, China
}

\begin{abstract}
In recent years, many experts and the media frequently said that the "big data" era is coming and innovation of network education also is inevitable. Facing the era of big data with the overwhelming mass data, it cannot be avoided in the process of difficult problems in the future education reform. It is very important how to effectively measure, discovery, evaluation and manipulation of information accumulation of learning management system. By analyzing the characteristics of big data, this paper presents the new model which including the application value and the construction of network education and the goal of evolution. Based on understanding the construction of network education confronting challenges, it is very important how to find this opportunity, do well the construction of network education and promote the integration of information technology and education under the idea of big data. For the problem of education, education methods and means of education will be changed and some new ideas and methods are put forward for network education method for Big Data. The paper presented the Model of Network Education in the age of Big Data (MNEBD). Finally, based on the development trend of large data, we predicted that Internet education data will play an important role in the forthcoming education.
\end{abstract}

Keywords-big data; data management; network education; research method

\section{INTRODUCTION}

With the new information in blogs, social networks, location-based services LBS as the representative of the publishing mode, cloud computing and Internet of things technology continuing to emerge[1]. When the constant growth and accumulation of data are of hitherto unknown speed, the era of big data has come to. Governments and companies have begun to pay close attention to the problem caused by big data.

In terms of academic field, Nature has launched the Big Data special issue in 2008 [3]. In 2008, Computing Community Consortium published a report "Big-Data Computing: Creating revolutionary breakthroughs in commerce, science, and society" [4], which describes the research background in big data driven, solve the problem of big data required technology and some challenges. Science launched "Dealing with Data" special issue in 2011, which mainly discusses the problem caused by big data in scientific research and instructions for the importance of scientific research [5]. In USA, a number of well-known experts and scholars jointly issued a white paper "Challenges and
Opportunities with Big Data" in the field of data management of professional point of departure [6].

From the academic point of view, the white paper introduces the data generation, analyzes the process of big data, and puts forward some challenges of big data. In Last June, the global well-known consulting company McKinsey (McKinsey) presented a big data detailed report "Big data: The next frontier for innovation, competition, and productivity", the influence of large data, the key technology and application fields have carried out a detailed analysis [7].

Since 2012, attention for big data is increasing. In January at the world economic forum in Davos, big data is one of the main themes and the meeting also especially for large data released the report "Big Data, Big Impact: New Possibilities for International Development", which discusses the new data generation mode, how to use the data to generate good social benefit [8]. The report focused on the use of fusion and mobile data generated by the individual and other data. In March, United States Obama government issued a " Big Data Research and Development Initiative" [9], more than $200,000,000$ of the investment dollars, officially launched the "big data development plan". The plans will be to use big data technology in scientific research, biomedical, environmental, and economic and other fields of breakthrough. The Obama administration's plan is one of the important measures, which are seen as the United States government following the Information Highway program in the field of information science.

At the same time, a global named Pulse initiative of the United Nations released the report "Big Data for Development: Challenges \& Opportunities" in the year [10]. The report mainly describes the face of data stream (Data Deluge) opportunities and challenges encountered situation of all countries in the age of big data, especially developing countries. At the same time, the application of big data has carried on the preliminary interpretation. "New York times" article "The Age of Big Data" by the mainstream media publicity is to make ordinary people to begin to realize that big data exist, and large data impact on people's daily life [11].

In 2012, the preparation of the Ministry of Education issued the "education normalization ten year development plan (2011-2020 year)" [12]. It identified the need to educational information to promote the modernization of education as a strategic choice to promote the integration of depth of 
information technology and teaching, realize the education thought, idea, method and means of all-round innovation. Construction of network education as a basic education plays an important role in the modernization of education question. Construction of normalization of education demand promotes the progress and updates the relevant technology. The evolution of technological progress promotes the construction of network education concept and connotation of the deep. In the different times from different perspectives of researchers, information technology, such as FDDI, ATM GPON-FTTH (FTTO) and SOA, can improve the network education network architecture, technology and equipment, application platform, construction mode and education teaching reform etc. So, Big data technology is the same. Today, with the big data era, the construction of network education will usher in another technological and ideological change. In this paper, analysis of network education in the age of big data construction is faced with opportunities and challenges, puts forward the target, contents and strategies of the construction of network education.

In this paper, we propose a Model of Network Education in the age of Big Data (MNEBD). The rest of this paper is organized as follows. Section 2 introduces the Model of Network Education in the age of Big Data(MNEBD). Section 3 describes the Research and Analysis on network education method for large data. Conclusions and future work are finally drawn in Section 4.

\section{MODEL OF NETWORK EDUCATION IN THE AGE OF BIG DATA (MNEBD)}

The model of network education in the age of big data (MNEBD) is shown in the figure 1. The MNEBD model consists of a large number of teachers, students and information databases. In the early days, the role of teachers is as the knowledge provider, while the role of students is learning knowledge. The teacher carries on the appraisal to the network knowledge. The teachers present its ideas, thoughts, ideas, and so on. Students can learn knowledge, following the teacher's ideas, thoughts and ideas. Then, students submit their learning experience to the teachers. After the teacher feedback, the study results are unquestionable. This process is analogous to the traditional model.

The role of teacher and student is changeable in the MNEBD model. Under certain conditions, the roles of teacher can convert into the roles of student in the condition of big data, as shown as in Figure 2. When students are learning gradually deep down, their knowledge structure will change. The teacher didn't know any more a part of the new knowledge that they are learning. The teacher will change into the students for the knowledge. Compare to the traditional model, the process of transition is very fast.

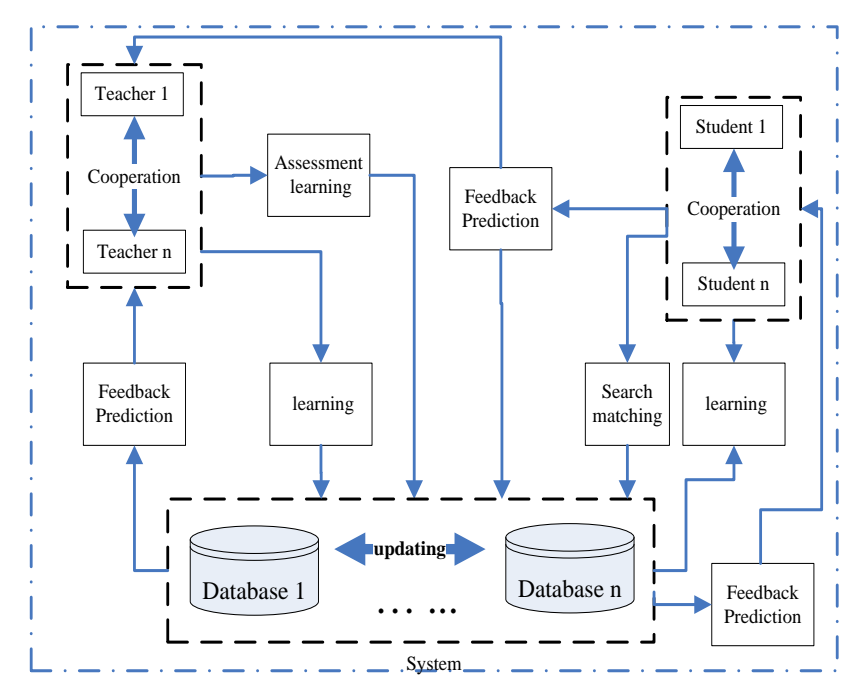

FIGURE I. MODEL OF NETWORK EDUCATION IN THE AGE OF BIG DATA (MNEBD).

\section{RESEARCH AND ANALYSIS ON NETWORK EDUCATION METHOD FOR LARGE DATA}

In the network of big data, there are several characteristics: As much as possible data, very fast update of knowledge and so on. All people, physical data can bring more data; have the characteristics of large data with data analysis, the concept of. Prediction function and application value can reflect the large data. Prediction function and application value can reflect the large data. Big data will reserve has play a decisive role to the development of the development of network education and the future of the school, large data construction, let the big data into the reform of education and teaching reform, learning environment, enhance teaching effectiveness, rich and convenience of modern scientific research data, the basis of Education Management, most can manifest the let the data speak of objective, true, scientific, credible practice spirit, the spirit of scientific research and scientific decision-making role.

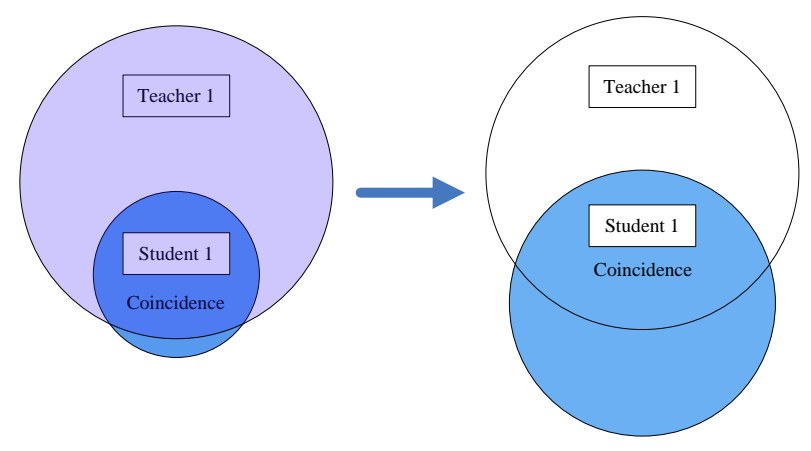

FIGURE II. THE ROLE OF TEACHER AND STUDENT IS CHANGEABLE.

\section{SUMMARY}

The big data era, to the informationization of education, information technology and the educational teaching depth fusion, brings the opportunity to the reform of the teaching mode of education and the cultivation of innovative talents. Data for all levels of the education system, education policy, 
education planning, education investment, education management, education and scientific research provide convincing reference, realistic and real-time evaluation, and provides a new tool, the ultimate aim is to optimize the education effect and the realization of the educational value maximization, reflecting the value of big data.

On the basis of big data technology and ideas, the paper presents the target, contents and strategies of the construction of a new period of network education. The development of network applications, cloud computing, Internet of things, let the data showing explosive growth, but does not mean that we have mastered the acquisition method of large data, grasp the large data analysis and application ability. As a practitioner of education management and education information construction, network construction of education requires us to have a strategic vision and practical spirit, face the challenge, grasp the opportunity. Domestic research on large data, storage technology, analysis and model processing is still relatively small, but with foreign different time is not long. Can foreknow, research and application on network education method of big data in China is in the preliminary stage, but the future will become one of the application and the research hotspot of network education in the construction.

\section{ACKNOWLEDGEMENT}

This research was financially supported by Natural Science Foundation of China (No.61402376), the key of Scientific Research Funds Project of Educational Department of Sichuan Province (No. 13ZA0019), the key of Scientific Research Funds Project of Xihua University (No. Z1222623, Z1322622 ), the Scientific Research Funds Project of Science and Technology Department of Sichuan Province(No. 2013JY0089, 15JC0117), the Fundamental Research Funds for the Central Universities (No. SWJTU12BR045), the key Funds Project of Sichuan Provincial Department of Education(13zA0019), the Scientific Research Funds Project of " Chun Hui " plan of Ministry of Education of China(No. z2014051), the Foundation of Cyberspace Security Key Laboratory of Sichuan Higher Education Institutions (No.sjzz2014-077) and Teaching Reform Project of Xihua University.

\section{REFERENCES}

[1] DeKosky, Steven T. The role of big data in understanding late-life cognitive decline: e unum, pluribus. JAMA neurology, 71(12), pp. 14761478, 2014.

[2] Einav Liran, Levin Jonathan. Economics in the age of big data. Science (New York, N.Y.) , 346(6210), pp. 1243089, 2014.

[3] Nature. Big Data [EB/OL].http://www.nature.com/news/spec ials / bigdata/ index.html

[4] Randal E. Bryant, Randy H. Katz, Edward D. Lazowska. Big-Data Computing: Creating revolutionary breakthroughs in commerce, science, and society [R]. http:// www.cra.org/ccc/docs/init/ Big__ Data.pdf

[5] Science. Special Online Collection: Dealing with Data [EB/OL]. [201210-02].http://www. sciencemag.org/site/special/data/

[6] D. Agrawal, P. Bernstein, E. Bertino, et al. Challenges and Opportunities with Big Data - A community white paper developed by leading researchers across the United States[R]. [2012-10-02], http://cra.org/ccc/ docs/ init/ bigdata whitepaper.pdf

[7] James Manyika, Michael Chui, Brad Brown, et al. Big data: The next frontier for innovation, competition, and productivity[R]. http://www.
mckinsey.com/Insights/MGI/Research/Technology_and_Innovatio/ Big data_The_next_frontier_for_innovation

[8] World Economic Forum .Big Data, Big Impact: New Possibilities for International Development[R].http://www3.weforum.org/docs/ WEF_TC_MFS _Big DataBigImpact_Briefing_2012.pdf

[9] Big Data Across the Federal Government [EB/OL]..http://www. whitehouse.gov/sites/default/files/microsites/ostp/big_data_fact_sheet_ final_1.pdf

[10] UN Global Pulse .Big Data for Development: Challenges \& Opportu nities [R]. http://www. unglobalpulse. org/projects/ Big Data for Development

[11] NY Times .The age of big data [EB/OL]. http:// www.nytimes.com /2012/02/12/sunday-review/big-datas-impact-in-the-world.html? pagewante $\mathrm{d}=$ all

[12] The Ministry of Education issued "the informationization of education ten year development plan (2011-2020)" notice http://www.moe.gov.cn/ publicfiles/business/htmlfiles/moe/s3342/201203/xxgk_133322.html 